\title{
From Waste to Usefulness: Packaging Design as a By-Product
}

\author{
Nataliia V. Skliarenko ${ }^{1 *}$, Anna S. Didukh², Viktoriia V. Rainysh ${ }^{2}$, Olena V. Kolosnichenko $^{1}$, Nataliia V. Chuprina ${ }^{1}$ \\ ${ }^{1}$ Faculty of Design, Kyiv National University of Technologies and Design, 2 Nemyrovycha-Danchenka Street, Kyiv 01011, \\ Ukraine \\ ${ }^{2}$ Institute of Architecture and Design, Lviv Polytechnic National University, 12 Stepan Bandera Street, Lviv 79000, Ukraine
}

Corresponding Author Email: skliarenko.nv@knutd.edu.ua

https://doi.org/10.18280/ijdne.160502

Received: 18 August 2021

Accepted: 24 September 2021

\section{Keywords:}

dynamical visual communication, ecological design thinking, environmentally friendly, multifunctional package, multilevel communicative environment, secondary use

\begin{abstract}
In this work we consider theoretical and practical aspects of packaging design as a byproduct. People can use it as a new design product with different initial functions. This study represents an important designers' contribution in solving environmental problems caused by excessive packaging waste. Author's methods of multifunctional package development analyze the market situation, research the wrapping design features, organize the author's concept, and evaluate the design product effectiveness. Methodological principles of the study are based on the design interpretation of the environmental, functional and socio-economical approaches context. The result of the theoretical study is the package design concept that increases the possible duration of packaging use. The specific design aspect of this study is the creation of different multifunctional packages, for example: package-constructor, package-board game, package-accessory. These design aspects make it possible to form a dynamic communicative visual environment. The author's design and development of a multifunctional package - constructor for pizza confirms the practical significance of the study. The results of this work are to show the popularization of environmental awareness education and increasing the level of social communication by involving emotional and game components into design process.
\end{abstract}

\section{INTRODUCTION}

A package is an integral part of each product. Increasing volumes of packing are intrinsically linked with the development of modern technologies and an explosion of varieties of consumer goods. Every year the wrapping production standards are higher. It is connected with requirements to the packaging quality for the purpose of product saving. The life cycle of packaging can be traced from producer to consumer and after that to the landfill. By throwing out it into the trash, we begin a chain of harmful impact on nature. It leads to the environmental pollution, which is becoming more critical every day. According to this, there is necessitates of changing the public consciousness towards more sustainable consumption patterns, which are connected with the buy of durable goods [1]. Nowadays the question of package design is strongly connected with the necessity of the environment saving. There already is a positive movement towards using resource-saving technologies. They are realized together with the closed processing cycle creation and also saving of different types of raw during the processes of production and using $[2,3]$. However, designers also aim to contribute to the environmental saving. They are looking for design methods to mitigate and overcome the huge problem of packaging waste. Nonetheless, it concerns not only the packaging materials recycling but also changing people's thinking and behavior according to the principles of sustainable design.

Manufacturers and designers often just intuitively look for environmental arguments for their package to convince consumers to buy goods and to educate appropriate behavior especially among the younger generation [4]. International package design competition "Mladý obal" became an important step towards solving the problem. Introduced in 1996, it takes place every year on the initiative of one of the package producers on the European continent [5]. It makes it possible to rethink not only technologies of the wrapping utilization but provides extension of its term of use. In other words, designers can give package the "second life". From this point of view, we can consider packaging as a by-product that is created by design tools. The justification of theoretical and practical aspects of packaging design as by-product shows perspectives for the future development of multifunctional wrappings from the standpoint of the environmental approach.

Environmental problems solving is also strongly connected with educational sphere that is engaged in training of design experts. The forming of the environmental consciousness should become the important aspect of their studying. The result of students-designers' creativity will be resistant projects that are created on the base of deep understanding of the nature state, social problems and engaging of interested people to sustainable solutions forming [6].

At this time, we offer the new view on design process which is aimed at education of environmentally safe behavior and strengthening of social communication. In this case, the ability to rethink ways of interaction between packaging and a consumer from design positions plays a huge pole. The accent on the environmental, aesthetic, functional and 
communicative functions of such a wrapping will provide an implementation of resistant designing decisions that has wide perspectives for development in the world. This study will provide the designing methods renewal and improvement of the tools for production of alternative packaging as a byproduct. It will change people thinking not only on the local level, but probably in global scale.

\section{METHODOLOGICAL CONCEPT OF THE STUDY}

Creating of a multifunctional packaging is a new concept which is just being introduced into production at the global level. Therefore, we offer the author's design method of such packaging. It includes the following steps which connects theoretical and practical aspects.

1) The first stage is the analysis of packaging material market situation from the standpoint of a systems approach. The study covers issues of demand and supply of the multifunctional packaging, developers and manufacturers, consumer needs, and also problems of environmental protection from pollution. Packages introduced at the international competition Model Young Package [5] and successful advertising developments of well-known Lee and Lay's brands [7, 8] became the source of materials for the analysis. We use these developments as analogues for the study of consumer features, technical properties or other design peculiarities.

2) The second stage is an analysis of design features of the different multifunction packing types that we carry out from the standpoint of environmental, functional and socioeconomic approaches.

On this research stage the critical analysis of packing life cycles from the standpoint of the environmental approach is important. According to the functional approach we have to pay attention to forming of basic design strategies of the alternative multifunction packing creation. They are based on possibility to increase the packing functions due to realization of game concept. According to the socio-economic approach we analyze the level of coordination of the visual component and production technology that is the important criterion of competitive products creation.

3) The third stage is forming of author's concept of the multifunction packaging that is based on the synthesis of the received information. It outlines the possibility of practical implementation of author's ideas. We suggest choosing the idea of playing activity that is game object or objects and rule of the game in order to create such project developments. Exactly on this stage the author's idea appears and the packaging image as game object created. And the rules of playing activity organized accord to the game object. In this way they allow to integrate environmental, functional and socio-economic requirements that were selected on the second stage. The choice of necessary design facilities will make communicative properties of packaging better. It is important to pay attention to essence package image and specific of its perception by people from different countries, races and age. We are sure that the artistic image should carry global features, however, it would be able to adapt taking into account the peculiarities of the brand, country or nation. The environment thinking as parts of design process is formed on this stage. It made to change consciousness and consumers actions in order to realize the author's idea in full.

4) The fourth stage provides an opportunity to explain the features which form the packaging structure. We highlight the artistic, structural and compositional, and technological features that reveal the essence of design product. Interpretation of design methods and principles takes place in the context of environmental, functional and socio-economic approaches. It allows creating a new eco-friendly package for secondary use that will realize not only wide design possibilities but also strengthens intercommunications between people by making dynamic visual communicative space.

5) The fifth stage is an evaluation of the design development effectiveness. On this stage it's important to choose the materials and technologies of package producing taking into account possibilities of secondary use, change of cost and flexible response to consumer requests. High economic efficiency of the alternative packaging is also associated with the possibility of brand's eco-friendly nature promotion by a producer. Moreover, the design methodology involves the use of multifunction packaging for increasing of visual communication dynamic that is aimed at solving the global packaging problems with the help of design.

\section{RESULTS}

On the basis of the mentioned author's methodology, we evaluated the effectiveness of environmental, functional and socio-economic approaches integration in the multifunction packaging creation process. Taking into account the principles of each one is important.

Ideology of ecological nature management is a mobile alternative to tendentious of society development. It is embodied during rethinking of society strategical actions. As a result, it contributes to the mastery of new design techniques. Scientific studies prove that on average consumers have low awareness about environmentally friendly package. Its perception is limited by three main aspects namely packing materials, industrial technologies and market attractiveness [9]

Any project idea should be evaluated from positions of the whole society interests and absence of the potential danger for the humanity development. On the design sphere this statement is transmitted in the form of environmentally friendly packaging design concept [10]. Its determinative problem is a new values formation in the culture and consciousness in the society. That is why on the design level wrapping should be rated from the positions of the environmental thinking forming and ability of environmentally friendly design optimization on the base of life cycle rating methods (PLCA) [11].

We analyzed the packaging life cycles from the standpoint of environmental approach. As a result, we discovered that the first cycle "need - designing - production - consumption" is incomplete. It shows that after consumption package ceases to exist.

As opposed to it there is second packaging life cycle which is complete. It has the following steps: "need - designing production - consumption - utilization". The "production" step makes it possible to continue the package existence using searching method and innovative materials and technologies for the wrapping creation (package from eco-materials, edible package, bio-decomposable package). They will give possibility for eco-friendly utilization. The "consumption" gives possibility for creation of package as a by-product on the base of design methods involvement by making changes of its 
functionality. It is probably the most perspective for the designers' activity. The "utilization" step, in turn, provides using package as material for new production cycle.

Packaging as a by-product is a package that after product consumption can be used as a new design object, which is not connected with packaged product. The designer's goal is to give package the "second life" to avoid utilization step. There are many examples in which under the influence of design wrapping prolongs its term of use thanks to the environmental essence that is embedded in it $[5,7,8,12]$. For instance, a person can re-use a wooden package from a bottle of alcohol as a bird feeder or a pencil case for student. So, designers create an idea that provides not only aesthetic and functional features appearance, but also connect environmental aspect and designing process.

The designing conception of package as a by-product makes people rethink functional side that is based on the transformation of its life cycle. The main idea is that packaging that performs its functions longer leads to reduction of the stimulus for re-production. In accordance it needs functions range expansion. Wrapping as a by-product not only protects the product, but also in the future people will use it as a new thing.

We analyzed the samples and found that it is possible to use package again on the base of using the concept of play. Play is the simplest activity in which people form their individuality and discover subject environment through the ability to receive positive emotions and satisfaction. We use it as a tool for creation figurative solution of packaging as a compositional structure and as a way of thinking for its solution process organization.

The package designing is based on the aesthetic function as well, which means improvement of its visual characteristics. According to Zeng et al. (2021) [13] studies, eco-package can help to decrease the amount of food waste at the expense of accent transfer during designing namely on the visual package attributes instead of social and commercial functions. Increase of wrapping visual characteristics is connected with the using of compositional tools and methods. Choice of effective packaging composition method is based on the chosen artistic and constructive solutions that are associatively approximated to the product. Methods of dynamic structural formation provide the ability of package construction transformation that forms interest in the product.

From the economic and environmental points of view it is a wrapping that doesn't have validity and people can use it many times. Moreover, during the transformation process the wonder and interest appear and the people's ability to communication increase.

The idea of production of package as a by-product should be agreed with production technologies, economic interests and social demand. Packaging industry should adapt to the market requirements and comply with global ecological requirements and sustainable development goals set at the international level [14]. Benefits determination of the package of one or another construction for consumer is connected with the formation of an effective market strategy of products popularization that we can easily implement using design. The visual component and production technology harmonization is an important criterion for the creation of competitive products.

All the described theoretical approaches are important for the practical implementation of the concept of packaging as a by-product. The result of the study is the development and creation of the pizza package designed by Viktoriia Rainysh as part of the master's thesis in 2020. Described methodological positions found the embodiment in the artistic image, the choice of structure and composition of the package.

An idea for the pizza package and a method for its realization. Nowadays takeaway products are very popular. Pizza is a common product all over the world and often ordered as a carryout. However, a pizza box takes up a lot of space and it needs to be utilized or recycled. The desire to continue its life cycle caused the development of the alternative package that people can use during table games.

This development is based on the concept of home town, urban landscape where we always live, work, have fun, spend our leisure time, communicate with others and eat. City is a center which we can fill with our own history and create many streets and fill them with movement and native rhythms. This concept is multifaceted. It helps not only children, but also adults to feel themselves in a childhood again. In addition, it can become the tourist attraction for guests. The elements of buildings, roads, cars, trees and people show scale of the environment and the perspectives of its development.

The city image makes it possible to realize the environmental approach in design at the subconscious level and educates environmentally friendly thinking using a game. In addition, it realizes functional approach and expands the wide range of possibilities of a simple package that used to be garbage. Moreover, package as a by-product allows rethinking people's relationships in society. It induces to communicate with each other and distracts from different gadgets.

The conception of the package-constructor makes it possible to build whole urban environment from 56 different elements that are printed on the inside of the box (Figure 1).
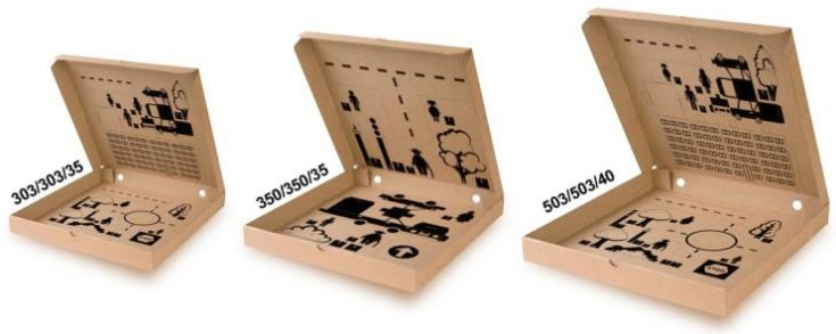

(a) Visualization of the pizza boxes
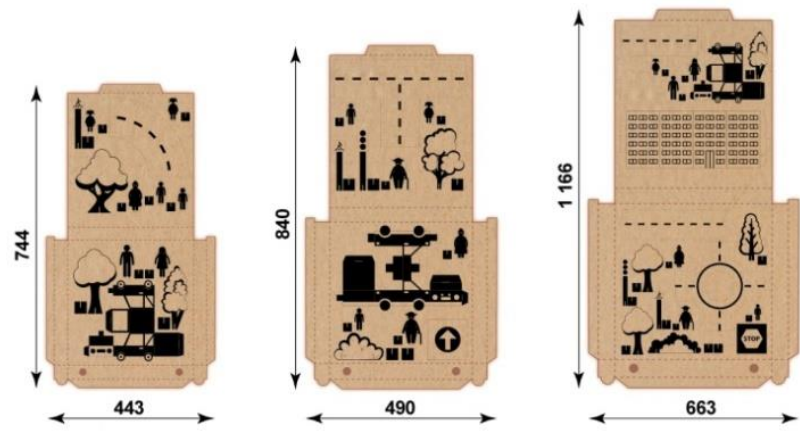

(b) Scan of the pizza boxes

\section{Figure 1. The pizza package designed by Viktoriia Rainysh}

There are trees and bushes, cars and trucks of different kinds, infrastructure objects, roads, road signs and additional attributes. Using these elements, we can create an urban environment. People are an important part of any city. This is why pictures of children, young people, older people and pets, like cats and dogs, are included in the development. This set of different elements demonstrates needs of people of any age, social and gender affiliation in society. It emphasizes the 
universality of the city's image (Figure 2). It encourages people to spend time together. It increases social communication. In general, this concept allows creating the multifunctional design product.

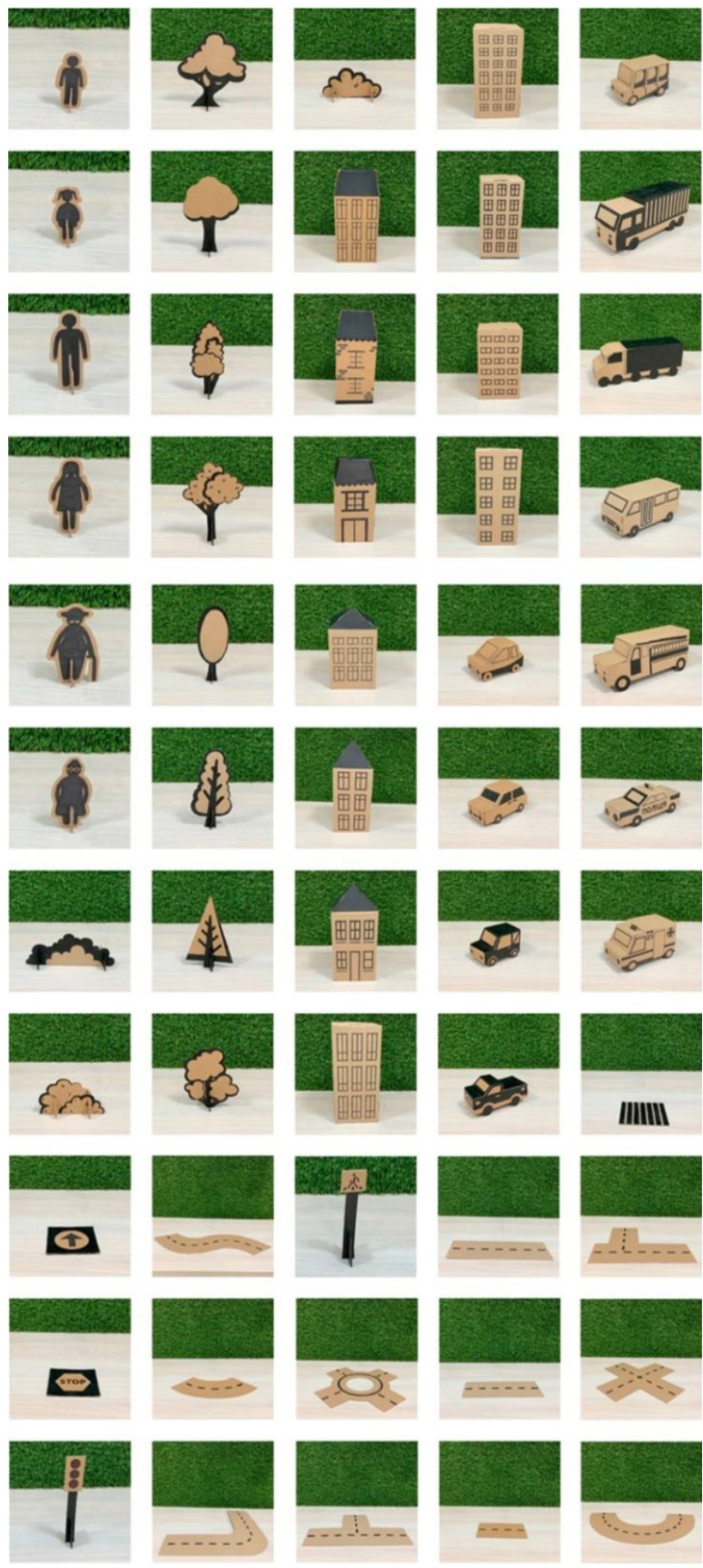

Figure 2. Various hand-made elements to play

We can build bigger and bigger city from collected pizza boxes, fill it with new objects and simulate new processes (Figure 3). The random selection effect of game elements minimizes an aesthetic fatigue and activates positive emotions. Along with pizza a consumer receives a free game with further possibility to collect hand-made eco-friendly toys. In addition, further designer's work will provide uninterrupted game elements renewing in direction of trademark recognizability level increasing.
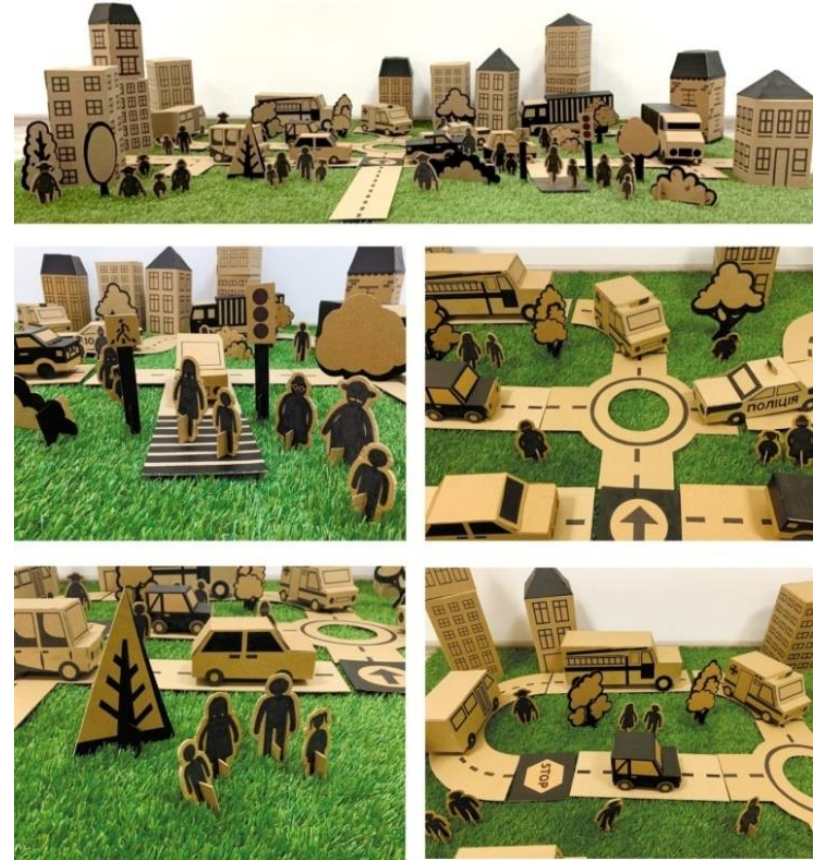

Figure 3. Visualization of the urban environment

Structural and compositional features. On the inside of each pizza box there are about 1-5 elements, which after cutting and bending on the given lines, form creative objects. We can create each element without any glue or other additional materials. For the creation of urban environment elements from the carton box we use methods of drafting, cutting and bending. The development includes volumetric objects, which are designed in such a way that people form clipped elements intuitively. So, there is no need for the special instruction for drafting. A small message or sticker will allow pointing consumer attention to additional functions of packaging.

Color is an integral part of the product packaging. It emotionally causes the decision about purchase. The pizza box-constructor has black and white image to make it more prestige and official. Only particular elements have black filling. It facilitates the object perception on the background of corrugated cardboard. Such a basis gives possibility to realize educational and relaxation function in the wrapping. The contour elements' drawing provides the possibility to paint them alone or in a group of game participants. It forms our own city environment perception, fills it with color and outlines the desire to change the world. The coloring process has anti-stress effect, positively effects on people, relaxes, stimulates the thought process and gives inner peace [15]. The drawing of elements with black color programs consumers to manipulate with depicted objects for the process of environment creation to be dynamic.

Technological features of production. We chose ecofriendly packaging material. This is a three-layer micro corrugated brown cardboard, which is suitable for recycling and does not harm the environment during decomposition. This is the best choice of material because the aesthetic and functional side of the package is important for the consumer. Hand-made products from this cardboard are eco-friendly, qualitative, aesthetically attractive, and suitable for exhibiting in the collection. It is even possible to improve the quality of micro corrugated cardboard with a minimal increase in the packaging cost at the expanse of the chalk layer application and using of full-color flexographic printing. It will form a positive image of the manufacturer. 
To reduce the packaging cost, it is possible to choose ordinary corrugated cardboard, which also has enough strength, protects the product from external influences, and is convenient for printed images applying on the outer and inner package surface. It is a cheap option without losing the visual images quality to attract a significant number of low- and middle-income consumers. Producer usually determines the quality of materials and printing technologies.

The pizza box conception can be realized on the packaging boxes of any sizes. The number of details that it is possible to receive after the product consumption depends on the box size. The bigger the box is, the more details there are. In this project we used boxes of three sizes: 503/503/40 mm, 350/350/35 mm, 303/303/35 mm.

The technology of image drawing on carton boxes is offset, screen printing or flexographic printing. Their advantages and disadvantages are connected with color rendering, quality, circulation and price and are determined by production capacity. The printing in the manufacture of 1000 units at a time is the most cost-effective for this project. It is possible to use elements' perforation that people make using laser equipment on printing companies. This makes it easy to separate the required elements from the cardboard base in order to facilitate the process of an urban environment creation.

Marketing strategy of product sales. Except the creative idea this concept of package-constructor has the base of socioeconomic requirements. It realizes consistent marketing strategy. We predict the raise of social interaction between parents and children and between children of different ages. It will increase product sales at the expense of interest of getting a new toy, not only a dish. One more strategic advantage is dependence of the elements' size from the box size. On big pizza boxes there are bigger toys and number of them is larger than on the small ones. It is economically profitably of food establishments.

High economical efficiency of an alternative wrapping is related with own production branding and production of original package as well. On the other hand, each brand can easily adapt the visual range to their own style ordering the design services (in compliance with intellectual property rights). So, they conserve the uniqueness or specific features of their brand. After all, the visual elements of the urban environment have different shape, size, color, and at the same time they are universal, while remaining recognizable houses, trees, cars, or people. In this way, the brand will get the properties of dynamic identification that makes its image better.

\section{DISCUSSION}

Today practical realization of package as a by-product outlines several notable trends in visual communication design.

\subsection{Multifunctionality of wrapping as a by-product}

In design of packaging as a by-product the ability of multifunctionality phenomenon rethinking through the use of composition methods and techniques comes to the fore. Now, when package assortment is various (from easy to difficult composite decisions) we can make sure that availability of another function after product consumption is an important benefit for a consumer. Using of the game concept helps designer to endow wrapping with diverse and associatively related with product and consumption process functions. Depending on game essence, composition and rules we consider the ability of dynamical structural forming of package of different kinds with game function.

1) Package-constructor. The idea to use different types of unified elements and combinatorial forming methods are main ones in the base of designing of package-constructor as a byproduct. They allow making three-dimensional construction that is suitable for games or another practical using.

2) Package-board game. The designing concept of this wrapping provides specific game activity with certain rules. The base of the design is placing of game board on the reverse side of the package and availability of counters or other elements for the board game.

3) Package-accessory. Package-accessories are the alternatives for photo session entourage or room decoration. Accessories of appropriate direction (e.g. mustache, eyes, lips, bows, etc.) that we can use as masks for a party and attributes for photos allow making selfie with product package. Such a functional approach is a planned continuation of the advertising company of this product.

Evidently thanks to visual communication tools using package as a by-product acquires the ability to perform many functions. Function of product protection, or storage, is the most important function of primary wrapping. That is why for the package as a by-product it loses sense. Dominant become functions that are not related to the received product.

Firstly, identification, advertising and information functions, realized through the attractive package design, help to identify the product, inform consumers about functional abilities of the wrapping as a product for the alternative using. It contains additional constructive elements for the transformation into another design-object. For example, Anna Kapi and Adam Matyikanics (Hungary, Eszterházy Károly University, 2017) designed the package for sunflower seeds called "Foodnook" that is a bird feeder [12]. Thanks to considered construction detalization people can easily percept changing of the box into the bird feeder and intuitively understand it.

Secondly, because of the intensive package industry development or environmental function, connected with problems of recycling, utilization or secondary use without any damage for the nature is in the foreground. Due to the wide spectrum of functions various kinds of wrappings become more and more popular today and people use them for other purposes. Even names of such packages often meet the realization of environmentally friendly function. For instance, Indian agency Happy Creative Services designed shopping packaging for the popular brand of clothing and accessories called "Lee". This bag, called "Never Wasted Bag", can transform into different useful items (e.g. pencil holder, bookmarks, games, images with recommendations, accessories for photos, toy cubes, etc.) by cutting of the bag along the dotted lines [7]. Unfortunately, now such packages do not enter the wide consumer market, but such a designing strategy has a good potential in the future. It will minimize waste and reduce harmful effects on the environment.

Thirdly, package as a by-product help to activate functions, related to person's existence in the world namely growth, studying, psychological state stabilization and communicative skills forming [16]. The variant of multifunctional package, designed by Viktoriia Rainysh, is just like that. Through the game this wrapping becomes radically different designproduct with various features that are not provided by product. It teaches children to think, build, design objects by cutting, 
drafting, bending, etc., explains traffic rules or behavior in an urban environment. Package-constructor plays a role of educational simulator, helps to build new toys for games, collect new and new elements and form our own game rules. In this way it promotes creative thinking development.

Multifunctional package has relaxation function as well. People can use it as anti-stress coloring book because it is possible to color elements that are created during the cutting and drafting processes. Moreover, except constructive changes packages of this type provide the possibility of game activity that encourages to social communication.

Functions of the package as a by-product become the part of the development of modern self-service norms, life style and project process and production. Functionality goes beyond single use, acquires multifunctional character and attracts people's attention with the possibility of getting several products instead of one. Methods of dynamical structural forming are often followed by artistic image change.

Compositional tools and methods that determine forming and pictorial features provide package multifunctionality accomplishment [17]. The compositional methods such as cutting, drafting and combinatory are the basics of designing of package as a by-product.

Method's essence of package cutting is form division into main and additional elements. Received elements allow creating a new product. It is laid down in the original forming concept as visual marking. For example, after product using we can cut images of accessories and decor elements that are applied to the outside or inside of the package and use them for new purpose.

Alternative consumption features of package appeared because of drafting methods. For instance, Greek designer Matadog created the model of juice package. We can transform it into the paper toy. After the consumption it is possible to disassemble the package and turn it inside out. Then we will get one of 12 designer's toys [18].

People use combining methods in design of package with alternative features which form intuitive search of various combinations of separate details according to created concept. Combining method is drafting of integral objects from set of different elements. The most effective detail choice is geometric shapes that make it possible to create volumetric dynamical packages-constructors. We change item's look using composition, colors, and ways of combining and decorating of elements.

\subsection{Packaging as a communication environment in the context of design}

Communication of consumer and package starts when person sees it in a shop. Wrapping becomes an efficient communication tool that increases process of information exchange and has an emotional influence on consumers [19]. Interaction processes of different types force the buyer to make a decision about purchase and further using of an item. So, we can talk about the package's ability to form the communicative environment with different communication levels.

Single-level communication often provides brief interaction of package and consumer. Usually, it is creation of new handmade products from package and their using for photos. Creators used the principle of decorativeness in designing of packages-accessories. It prepares material for manifestation of creative abilities in decoration of house, creation of festive accessories and toys. After work performance the contact with new products is terminated or limited to individual photos.

Higher level of communicative features of package as a byproduct helps to realize the principle of complementarity. Manufacturers draw part of some unfinished image or leave some holes. The task of consumer is to supplement the holistic image intuitively. The base of its completion is using of associative connections. For example, brand "Lay's" created an advertising called "Create a million smiles", package series with the photo of the lower part of the smiling faces of men and women and a bit later the Lay's Smiles bags with a QR code [8]. In such a way a person becomes the part of a package and receives the ability to add their face to the image on a package with the purpose of taking photos. People can use one wrapping many times. The purpose of package as a visual communication tool is not only creation of a creative design, but also activation of people emotional sphere [20], improving of psychological state and relaxation. Moreover, such a package helps to advertise the product because it quickly appears in social networks. Person's involving to the communication allows continuing shelf life of the package as a by-product.

Multilevel communication makes interaction processes between people absolutely different and without time limitation using package. Communication has the base of the collecting principle. People have constant desire to get new packages not for product consumption, but for the realization of secondary packaging functions. The base of collection is the principle of modularity that makes it possible to create new objects using a certain number of basic (combinatorial) elements to obtain a by-product. Hungarian designer Zita Siran, who became the winner of package competition Model Young Package with the milk box called "Milk school", implemented this principle [5]. Her box became peculiar game unit for building of different constructions. The concept of this package reveals the social aspect of collective children's game. It is a great marketing move as well. For building of bigger construction people have to buy new milk packages. Similar aspects of multilevel communication help to implement the pizza box by Viktoriia Rainysh. Lots of people can collect combinatorial elements. Package that is a board game at the same time and provides uninterrupted people's communication during active spending of leisure time has the base of multilevel communication.

So, the principles of decorativeness, complementarity and modularity in packaging design effectively program the social people's behavior. As a result, wrapping as a by-product becomes the core that organizes different communicative processes and creates the multilevel communicative environment (Figure 4). The main strategies of its formation are customer behavior programming; formation of ecological thinking and increase of social competence.

We can achieve consumer behavior programming only through positive emotions and people's involvement to the game. Game moment is one of the most effective marketing tools. People often use it in the sphere of corporate communication and create funny and creative product packages. The base of a funny situation or idea is an association. It gives positive experience that makes memorization of goods easier and creates emotional communication [20]. Today the studies of the influence dependence of packaging visual characteristics on the age of not only adults but also children as potential consumers are becoming relevant to achieve greater efficiency of strategic communication [21]. Aspects of ecological thinking and social 
competence education are strongly connected with each other by project principles of environmental, functional and socioeconomic approaches. The final focus of the described strategies is the need to optimize the efforts and resources that people need for the harmonization of the environment, social culture and economic activity.

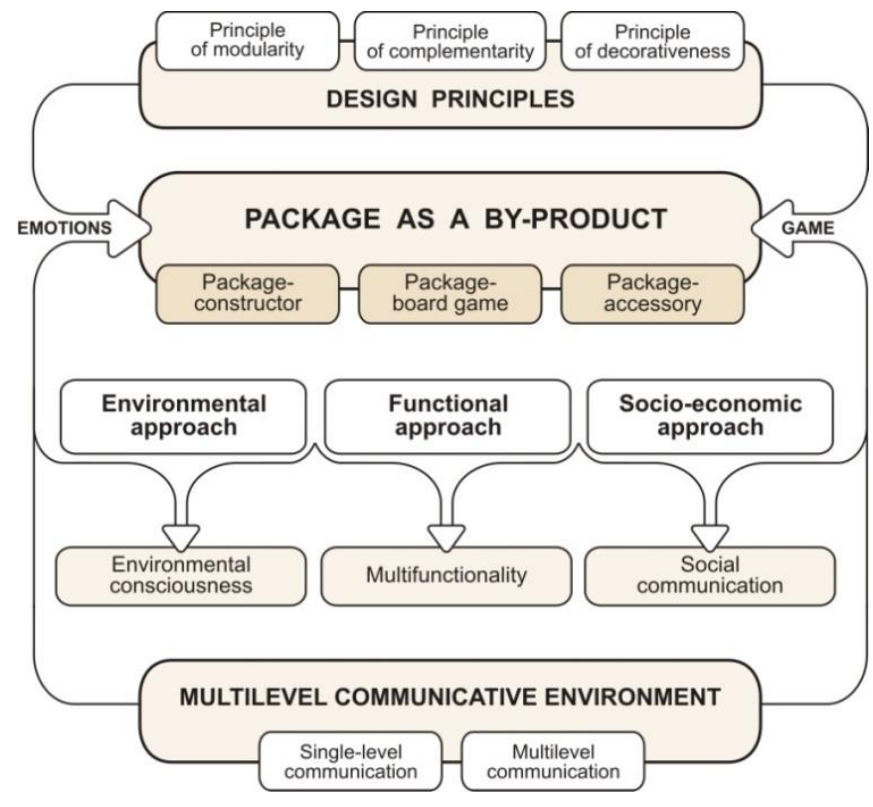

Figure 4. Features of packaging design as a by-product

\section{CONCLUSIONS}

In the study we revealed the essence of designing of a package as a by-product. It is multifunctional package. On the consumption step people can use it as a new object with wide functions spectrum that are not connected with packaged item. We believe that using design methods we can continue package's shelf life on the market thanks to transformation of consumption step in the full life cycle of packaging.

In the work we proved that ecological thinking is an important part of the project process. Ecological design concept is tolerated to the designing sphere of package. It generates ideas in the context of eco-needs of environment and society. Game process that encourages to creation of dynamical visual communication is the basic of designing of different types of packages (package-constructor, packageboard game and package-accessory) as a by-product. Wrapping multifunctionality has the base of compositional methods using (cutting, combining, drafting) and we create it using principles of decorativeness, complementarity and modularity. These scientific positions of the theoretical study formed the base of the practical design-development of author's pizza box

Designing of package as a by-product in XXI century creates the methodological basics of alternative wrapping design. It is aimed at educating of the environmentally friendly thinking and contributes to the increase of person's communication through positive emotions and play activity. Modern multifunctional package, suitable for use as a byproduct, are not on the wide consumption market yet. However, it becomes more and more popular every day. We consider the very attraction of attention of scientists, educational institutions employees, students and practicing designers as very valuable contribution of our publication.

\section{ACKNOWLEDGMENT}

Authors want to thank the employees of printing company "Svarog" (Lutsk, Ukraine) for professional consultations about concept harmonization of designing of package as a byproduct with technological methods of producing. We get finished wrapping as a result of theoretical research.

\section{REFERENCES}

[1] Guinot, J. (2020). Changing the economic paradigm: Towards a sustainable business model. International Journal of Sustainable Development and Planning, 15(5): 603-610. https://doi.org/10.18280/ijsdp.150502

[2] Franz, R. (2002). Programme on the recyclability of food-packaging materials with respect to food safety considerations: polyethylene terephthalate (PET), paper and board, and plastics covered by functional barriers. Food Additives \& Contaminants, 19(1): 93-110. https://doi.org/10.1080/02652030110085395a

[3] Cicconi, P. (2020). Eco-design and eco-materials: An interactive and collaborative approach. Sustainable Materials and Technologies, 23: e00135. https://doi.org/10.1016/j.susmat.2019.e00135

[4] Jerzyk, E. (2016). Design and communication of ecological content on sustainable packaging in young consumers' opinions. Journal of Food Products Marketing, 22(6): 707-716. https://doi.org/10.1080/10454446.2015.1121435

[5] Model Young Package. https://youngpackage.com/historie/, accessed on June 28, 2021.

[6] Ashour, A.F. (2020). Design responsibility and sustainability in education. International Journal of Design \& Nature and Ecodynamics, 15(1): 129-133. https://doi.org/10.18280/ijdne.150117

[7] Lee Never Wasted: la shopping bag ecologica. (2013). https://infographicsinreallife.wordpress.com/2013/08/02 /lee-never-wasted-la-shopping-bag-ecologica/, accessed on June 28, 2021.

[8] Kalkowski, J. (2019). Snack Maker's Smiling Pouches Highlight Charitable Individuals. Flexible Packaging. https://www.flexpackmag.com/articles/90085-snackmakers-smiling-pouches-highlight-charitableindividuals, accessed on June 28, 2021.

[9] Nguyen, A.T., Parker, L., Brennan, L., Lockrey, S. (2020). A consumer definition of eco-friendly packaging. Journal of Cleaner Production, 252. https://doi.org/10.1016/j.jclepro.2019.119792

[10] Zeng, T., Deschênes, J., Durif, F. (2020). Eco-design packaging: An epistemological analysis and transformative research agenda. Journal of Cleaner Production, https://doi.org/10.1016/j.jclepro.2020.123361

[11] Kamalakkannan, S., Kulatunga, A.K. (2021). Optimization of eco-design decisions using a parametric life cycle assessment. Sustainable Production and Consumption, $\quad 27$ : 1297-1316. https://doi.org/10.1016/j.spc.2021.03.006

[12] Mladý obal 2017 - výsledky sút’aže [Young Package 2017 - the results of the competition] (2017). https://www.archinfo.sk/sutaze/young-package-mladyobal-2017-vysledky-sutaze.html, accessed on June 28, 2021.

[13] Zeng, T., Durif, F., Robinot, E. (2021). Can eco-design 
packaging reduce consumer food waste? an experimental study. Technological Forecasting and Social Change, 162. https://doi.org/10.1016/j.techfore.2020.120342

[14] Monteiro, J., Silva, F.J.G., Ramos, S.F., Campilho, R.D.S.G., Fonseca, A.M. (2019). Eco-design and sustainability in packaging: A survey. Procedia Manufacturing, 38: 1741-1749. https://doi.org/10.1016/j.promfg.2020.01.097

[15] Dresler, E., Perera, P. (2019). 'Doing mindful colouring': Just a leisure activity or something more? Leisure Studies, 38(6):

$862-874$ https://doi.org/10.1080/02614367.2019.1583765

[16] Frascara, J. (2004). Communication Design: Principles, Methods, and Practice. New York, NY, Allworth Press.

[17] Pashkevich, K.L., Kolosnichenko, M.V., Ostapenko, N.V. (2016). Research of some physical and mechanical characteristics of suiting fabrics for designing the clothes. Fibres and Textiles, 23(1): 3-8.

[18] Embalagem diferente: se transforma em brinquedo, diverte e diminui o lixo [Other packaging: turns into a toy, entertains and reduces waste] (2016). http://cartonagemvision.com.br/noticias/embalagemdiferente-se-transforma-em-brinquedo-diverte-ediminui-o-lixo/\#more, accessed on June 28, 2021.

[19] Underwood, R.L. (2003). The communicative power of product packaging: Creating brand identity via lived and mediated experience. Journal of Marketing Theory and Practice, $11(1)$ : https://doi.org/10.1080/10696679.2003.11501933

[20] Liu, Y., Li, W., Yi, Z. (2016). Expressing emotional concept in visual communication design: An anthropological case study on emotional design in China. The Anthropologist, 23(3): 311-322. https://doi.org/10.1080/09720073.2014.11891951

[21] Zhang, D. (2020). Exploring age effects on children's preferences of package design: curvilinearity, figurativeness, and complexity. Journal of International Consumer Marketing, 32(5): 416-434. https://doi.org/10.1080/08961530.2020.1763886 